\title{
Hybrid polymer biomaterials for bone tissue regeneration
}

\author{
Bo Lei ${ }^{1}$, Baolin Guo ${ }^{1}$, Kunal J. Rambhia ${ }^{2}$, Peter X. Ma $(\bowtie)^{1,2,3,4,5}$ \\ ${ }^{I}$ Frontier Institute of Science and Technology, Xi'an Jiaotong University, Xi'an 710054, China; ${ }^{2}$ Department of Biomedical Engineering, \\ University of Michigan, Ann Arbor, MI 48109, USA; ${ }^{3}$ Department of Biologic and Materials Sciences, University of Michigan, Ann Arbor, MI \\ 48109, USA; ${ }^{4}$ Macromolecular Science and Engineering Center, University of Michigan, Ann Arbor, MI 48109, USA; ${ }^{5}$ Department of \\ Material Science and Engineering, University of Michigan, Ann Arbor, MI 48109, USA
}

(C) The Author(s) 2018. This article is published with open access at link.springer.com and journal.hep.com.cn

\begin{abstract}
Native tissues possess unparalleled physiochemical and biological functions, which can be attributed to their hybrid polymer composition and intrinsic bioactivity. However, there are also various concerns or limitations over the use of natural materials derived from animals or cadavers, including the potential immunogenicity, pathogen transmission, batch to batch consistence and mismatch in properties for various applications. Therefore, there is an increasing interest in developing degradable hybrid polymer biomaterials with controlled properties for highly efficient biomedical applications. There have been efforts to mimic the extracellular protein structure such as nanofibrous and composite scaffolds, to functionalize scaffold surface for improved cellular interaction, to incorporate controlled biomolecule release capacity to impart biological signaling, and to vary physical properties of scaffolds to regulate cellular behavior. In this review, we highlight the design and synthesis of degradable hybrid polymer biomaterials and focus on recent developments in osteoconductive, elastomeric, photoluminescent and electroactive hybrid polymers. The review further exemplifies their applications for bone tissue regeneration.
\end{abstract}

Keywords hybrid polymer; bone regeneration; tissue engineering; biomaterials

\section{Introduction}

The extracellular matrix (ECM) of native tissues is composed of a hybrid polymer nanostructure at the molecular level, organized with different biopolymers and nanocrystallites [1]. Due to their hybrid and wellorganized structure, both hard and soft native tissues demonstrate excellent physicochemical properties including viscoelasticity and strength. They also demonstrate excellent biological activity including cellular biocompatibility and tissue-inductive ability [2]. Development of new biodegradable biomaterials by mimicking the physicochemical properties and biological activity has therefore gained increasing attention in recent years [3]. Biomimetic polymer hybrid biomaterials play an important role because they can be synthesized with highly tailored physicochemical properties and bioactivity, through combining different polymers and inorganic phases at the multiple levels [4]. In past decades, biodegradable naturalbased polymers (collagen, silk, alginate, chitosan, hya-

Received December 4, 2017; accepted June 15, 2018

Correspondence: Peter X. Ma, mapx@umich.edu luronic acid) and synthetic polymers (poly(lactic acid): PLA, poly(glycolic acid):PGA, poly(lactic-co-glycolide): PLGA, Poly( $\epsilon$-caprolactone):PCL, Polyhydroxyalkanoates: PHA) have been widely studied and their promising biomedical applications are also well demonstrated [5-8]. These polymers have been hybridized in many forms including 3D scaffolds, hydrogels, microspheres, and their composites [9-14]. Hybrid hydrogel-microsphere polymers with osteoconductive properties have also been synthesized [15-17].

In addition to the hybrid structure, osteocondutive property and electroactive ability are also very important for the application of hybrid polymers to regenerate bone [18]. Regeneration of bone can be accomplished by a combination of osteoinductive materials, regenerative cells and osteogenic growth factors. Local and long-term treatment with bone morphogenetic protein 7 (BMP-7) was accomplished by encapsulation of bioactive protein in PLGA microspheres. In combination with a nanofibrous and porous scaffold, treatment with BMP-7 significantly enhanced in vitro osteogenic differentiation and in vivo bone regeneration [19].

Pure biomedical polymers such as those listed above cannot mimic the mechanical properties of native tissues 
especially the strength, elasticity and modulus, due to intrinsic shortcomings. Nevertheless, they provide certain advantages. It is possible to use these polymers to design precise micro and nanoscale environments that are beneficial for cell attachment, proliferation and differentiation. They can also be tailored for tunable drug delivery. Because of these advantages, they are being developed widely for tissue regeneration. To improve their mechanical and osteogenic properties, bioactive ceramic-based nanophases (bioactive glass and calcium phosphate) and various polymers (natural and synthetic polymers) have been hybridized [20-27]. To induce elastomeric behavior, highly elastomeric hybrid polymers were also synthesized through incorporating inorganic phase into biodegradable elastomers [28]. In particular, siloxane-based biodegradable hybrid polymer elastomers were developed with significantly enhanced mechanical properties and biocompatibility [29-31]. In recent years, electric stimulation has been shown to exhibit a positive effect on tissue regeneration through enhancing cell proliferation and differentiation [32]. Therefore, conductive components such as carbon-based materials and polymer semiconductors were added to fabricate electroactive hybrid polymer biomaterials for tissue regeneration applications [33].

This work reviews the design, fabrication, and properties of biodegradable hybrid polymers with a focus on their osteoconductive functions, elastomeric property, and electroactivity. The prospective application of hybrid materials for bone tissue regeneration is also covered in this review.

\section{Synthesis and properties of hybrid polymers}

\section{Osteoconductive hybrid polymers}

Osteoconductive hybrid polymer biomaterials can be fabricated by incorporating osteoconductive materials into biodegradable polymers. Biodegradable polymers typically have low elastic modulus and poor osteoconductive activity [34]. Bioactive inorganic biomaterials including bioactive glass (BG) and calcium phosphate (CP) have high conductive activity and bone-bonding ability, and their enhanced potential for bone regeneration have been well described in the literature [35-39]. Therefore, BG and $\mathrm{CP}$-based nanoparticles have been added into various polymers to fabricate osteoconductive hybrid polymers for bone tissue regeneration [40-43]. CP-based polymer hybrid biomaterials have been fabricated successfully by melting, solvent-casting and in situ precipitation [44]. Most reports showed that addition of low content-CPbased nanoparticles can efficiently improve the mechanical strength and modulus of polymers and improve osteoconductive bioactivity [44]. Bioactive glass nanoparticles (BGN) have an amorphous structure and typical chemical composition of $\mathrm{SiO}_{2}-\mathrm{CaO}-\mathrm{P}_{2} \mathrm{O}_{5}$ that enable the controlled biodegradation and high bone-bonding activity for in vivo implanting applications [45]. By the facile solvent-casting method, BGNs with different morphology and size were added into various polymers including gelatin, chitosan, PLA, PCL, PLGA [41,46-48]. These hybrid BGNpolymers significantly enhanced compressive strength, tensile strength, elastic modulus, biominerialization, and osteoblast biocompatibility (Fig. 1). Although BGNpolymer nanocomposites have been developed well in past years, the nanoparticle-based polymer composites still showed uncontrolled biodegradation and mechanical properties in vivo due to the low interface strength between nanoparticles and polymers. These are known challenges associated with certain BGN-polymer nanocomposites.

Advances have been made in hybrid polymer materials to maintain controlled degradation and mechanical properties while also enhancing in vitro osteoconductive activity [49]. Gelatin-apatite hybrid nanofibrous scaffolds fabricated by thermally induced phase separation were

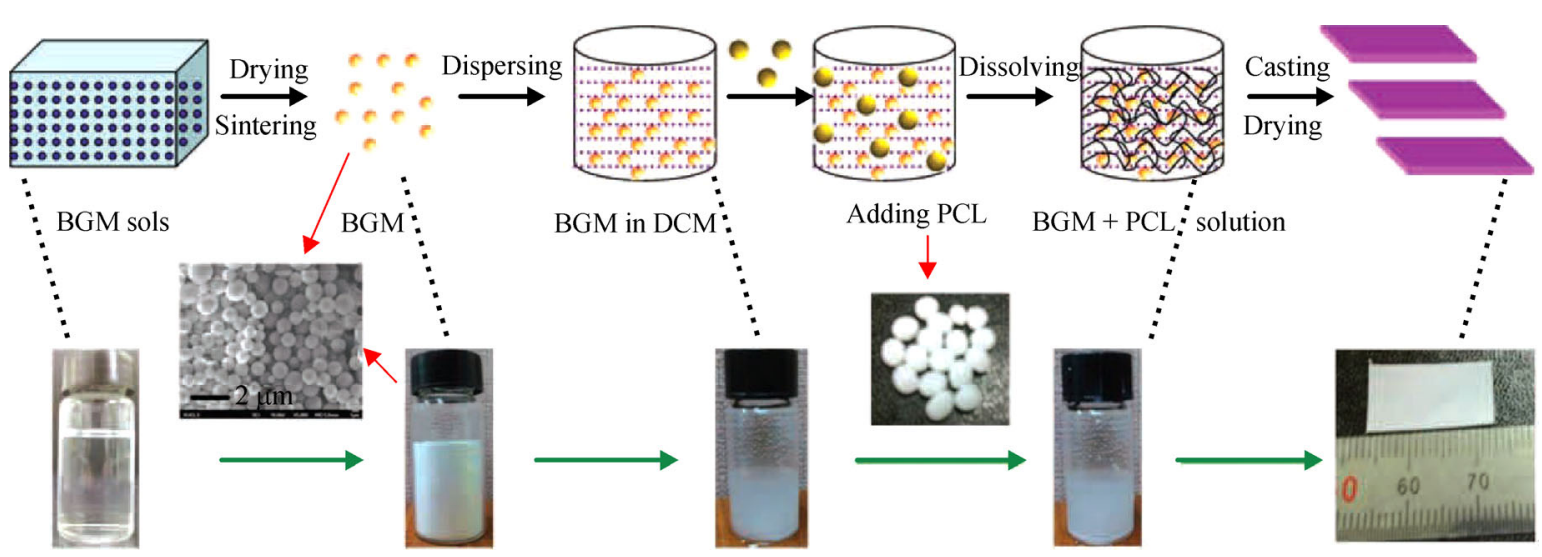

Fig. 1 Bioactive glass particles reinforced PCL osteoconductive hybrid polymers. Reproduced from Ref. [41] with permission. 
evaluated for biominerialization in simulated body fluid (SBF) [49]. The gelatin-apatite hybrid scaffolds demonstrated significantly enhanced mechanical strength and enhanced expression of osteogenic genes in cells. Additionally, the hybrid scaffold was coated with biological apatite nanocrystals through an electrochemical deposition technology (Fig. 2) [50]. The apatite layer thickness could be tailored efficiently by the electrochemical parameters. The deposited hybrid polymer scaffolds also showed enhanced physiochemical properties and osteoconductive activity.

Agglomeration of BGNs within the polymer matrix is a challenge associated with hybrid polymers, as these materials may exhibit unfavorable mechanical and physiochemical properties [43]. To overcome this limitation, silica-based bioactive glass sol (SBGS) at the molecular level has been used to develop hybrid polymer biomaterials for applications in tissue regeneration. For example, SBGS-reinforced gelatin, chitosan, polyethylene glycol (PEG) and PCL hybrid polymers have been fabricated successfully through one-step hybridization process [5157]. SBGS reinforced hybrid polymers showed significantly improved mechanical properties including strength, toughness, controlled biodegradation and biominerialization, as well as high osteoblastic activity. The SBGSreinforced gelatin hybrid polymer was synthesized through typical sol-gel process, and the interface strength between organic and inorganic phase was controlled by siloxane coupling agents (Fig. 3). The resulting SBGS-gelatin hybrid showed strong compressive strength, mimicking native bone tissue and providing evidence for its potential application in bone fixation and repair [51]. SBGS-based gelatin hybrid scaffolds and nanofibrous scaffolds were fabricated through alkaline treatment technology and thermal-induced phase separation (Figs. 4-6). Significantly improved mechanical properties and biocompatibility of SBGS-gelatin hybrids were observed [41,43,51,58-60]. The SBGS-based hybrid polymer biomaterials have shown promise for bone tissue regeneration.

Additional advances have been reported in the use of carbon biomaterial-polymer hybrids as osteoconductive scaffolds for bone regeneration. Carbon nanomaterials are often synthesized as single sheets, referred to as graphene, or hollow structures referred to as carbon nanotubes (CNTs). CNTs can be single-walled or multi-walled, consisting of concentric tubular layers of graphene. One study compared CNT-PLLA scaffolds with graphenePLLA scaffolds and reported that both carbon nanomaterial hybrids enhanced in vivo bone regeneration but graphene-PLLA scaffolds showed more osteoconductive capacity than CNT-PLLA scaffolds [61]. Polymeric scaffolds reinforced with ultrashort (US)-single walled CNTs enhanced both ectopic and in situ bone regeneration in rabbit subcutaneous and femoral condyle models [62]. Adsorption of ampiphilic comb-like polymer (APCLP) to CNTs allowed for more homogenous integration of carbon nanotubes into a bacterial cellulose (BC) scaffold [63]. In a mouse calvarial defect model, this hybrid CNT-BC scaffold improved bone formation and expression of osteocalcin. Vertically aligned CNTs combined with hydroxyapatite were made to be superhydrophilic and subsequently dispersed in poly (D, L, lactic acid) (PDLLA). The resulting hybrid scaffold showed suitable mineralization and cytocompatibility in vitro and demonstrated enhanced in vivo bone regeneration capacity in a rat calvarial defect model [64]. In addition to increasing

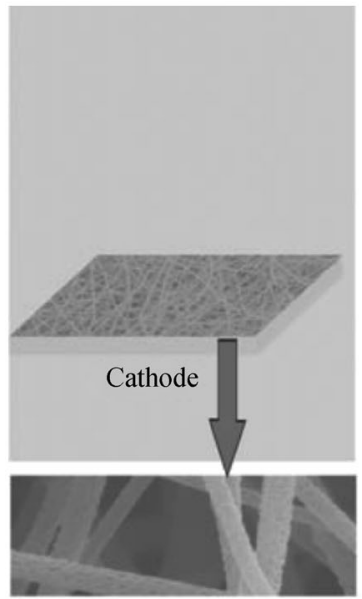

Time $=0 \mathrm{~min}$

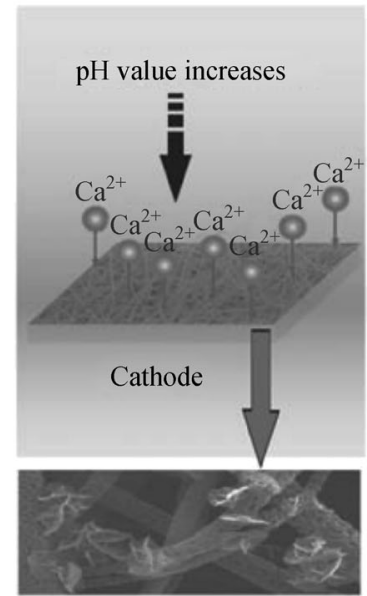

Time $=15 \mathrm{~min}$

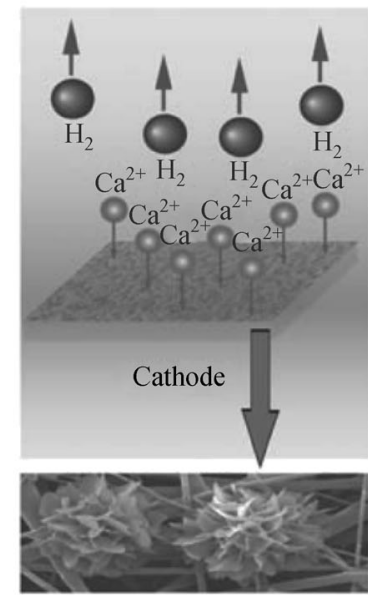

Time $=30 \mathrm{~min}$

Fig. 2 Schematic illustration of a hypothesized mechanism for the growth of calcium phosphate crystals over time. When a deposition voltage is applied, $\mathrm{pH}$ in the vicinity of electrode increases, and some calcium phosphate crystals deposited onto the surface of PLLA nanofibers. Further increase of deposition time leads to the generation of hydrogen bubbles and larger flower-like crystals. Reproduced from Ref. [50] with permission. 
A

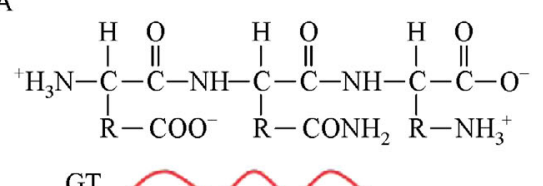

$\mathrm{D}$
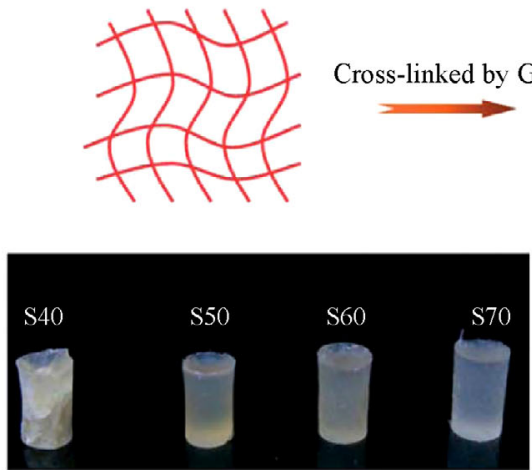

$\mathrm{B}$<smiles>CO[Si](C)(CCCOCC1CO1)OC</smiles>

$\mathrm{C}$
GS

$\mathrm{E}$

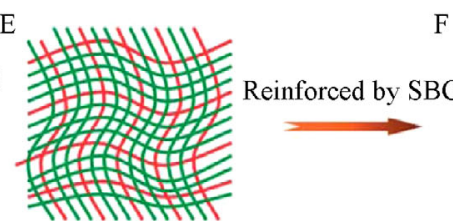

SBG O $\sim$

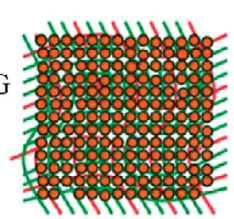

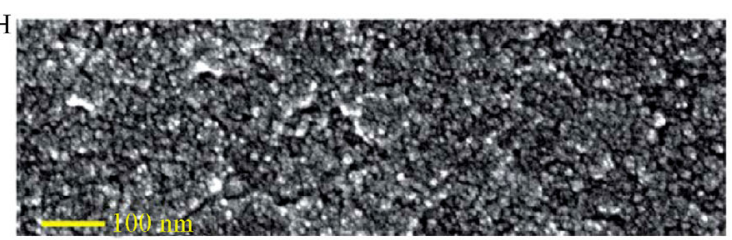

Fig. 3 Formation mechanism of the biomimetic siloxane-gelatin (SGT) hybrid bone implants. (A-C) Molecular structure and composition of gelatin (GT) (A), siloxane (GS), silicate bioactive glass sol (S); (D-F) GT (D) polymer matrix was cross-linked by GS (E), and then hybridized with the SBG sol at the molecular and nanoscale levels (F); ( $\mathrm{G}$ and $\mathrm{H})$ semi-transparent SGT hybrid implants with different SBG weight percent, formed after condensation and drying. Reproduced from Ref. [51] with permission from the Royal Society of Chemistry.

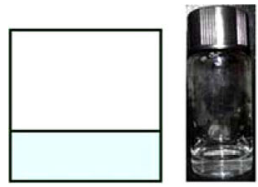

Hybrid solution

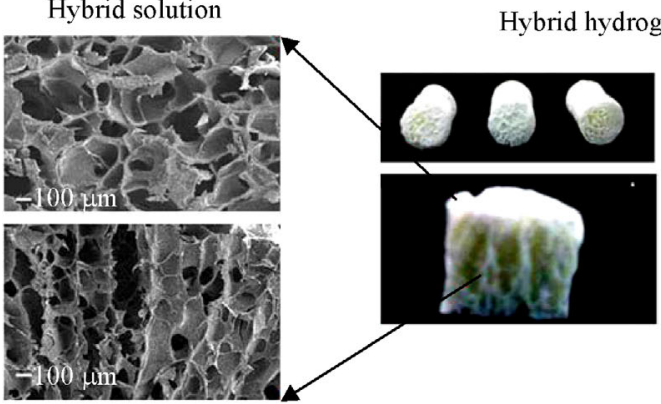

Hybrid scaffolds structure

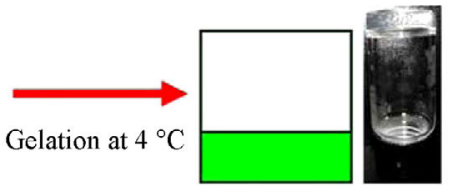

Hybrid hydrogels
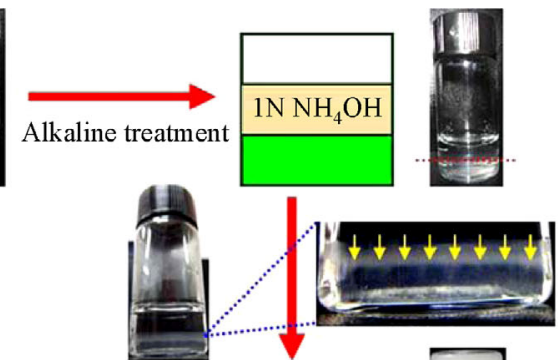

Dehydration process
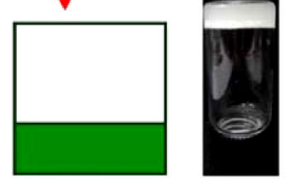

Alkaline treated hybrid hydrogels

Fig. 4 Schematic diagram showing an experimental procedure for producing anisotropic porous gelatin-silica hybrid polymer scaffolds by ammonium hydroxide treatment. Reproduced from Ref. [68] with permission.

hydrophilicity, functionalization of CNT-polymer hybrids may improve mechanical characteristics and cytocompatibility of scaffolds and was reported to enhance in vitro and in vivo bone regeneration [65-67].

\section{Elastomeric hybrid polymers}

Many tissues in the body possess elastomeric properties. Therefore, the development of biomaterials that demonstrate highly elastomeric behavior has garnered much attention. Elastomeric materials are of particular interest because of their biomimetic mechanical properties, which enable their use in the complicated in vivo load environment [69]. Current biodegradable elastomers include physically crosslinked polymers such as polyurethanes and polyesters, chemically crosslinked polymers such as poly(glycerol sebacate) (PGS) and poly(citrate diol) (PCD) [70]. These biodegradable elastomers have shown highly tunable degradation, moderate biocompatibility and good elastomeric mechanical behavior [70]. They have 

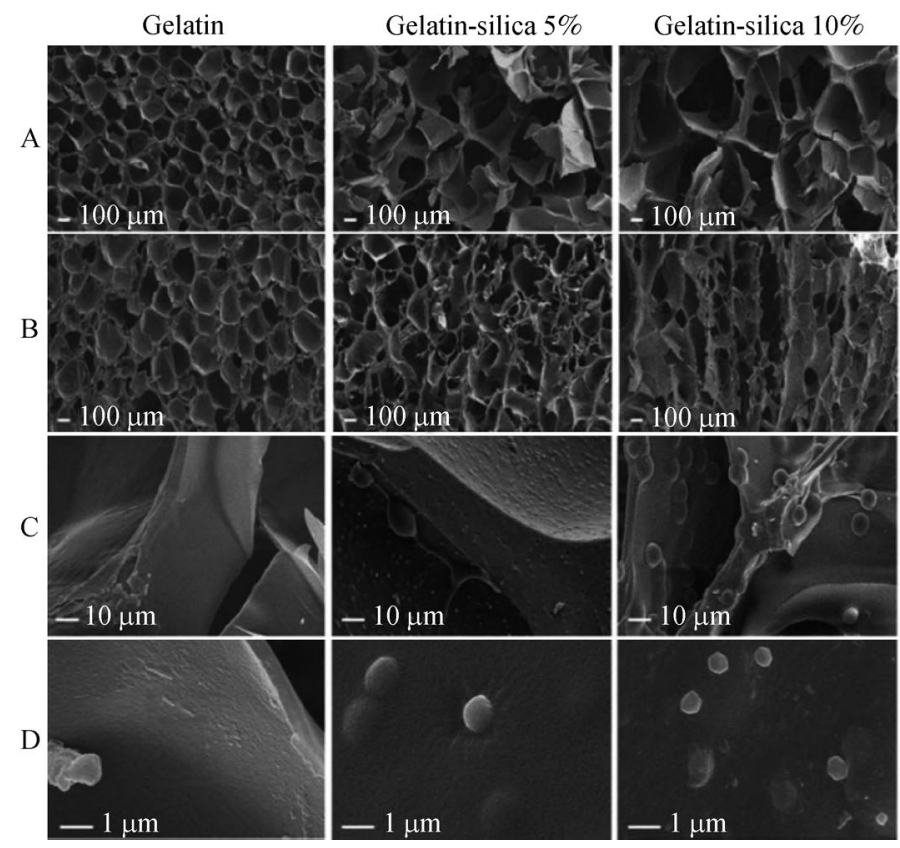

Gelatin-silica 20\%

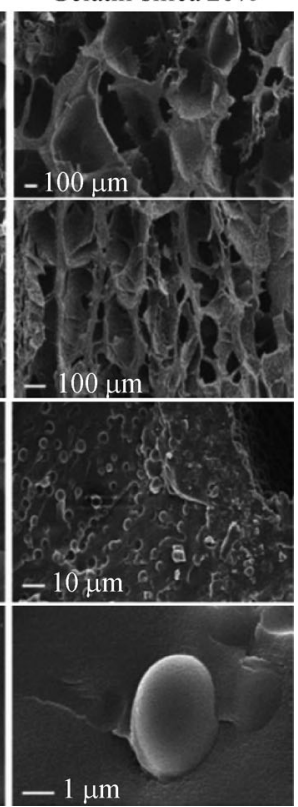

Fig. 5 Porous morphology of gelatin-silica hybrid polymer scaffolds. (A, C) Transverse direction; (B, D) Axial direction. Reproduced from Ref. [68] with permission.

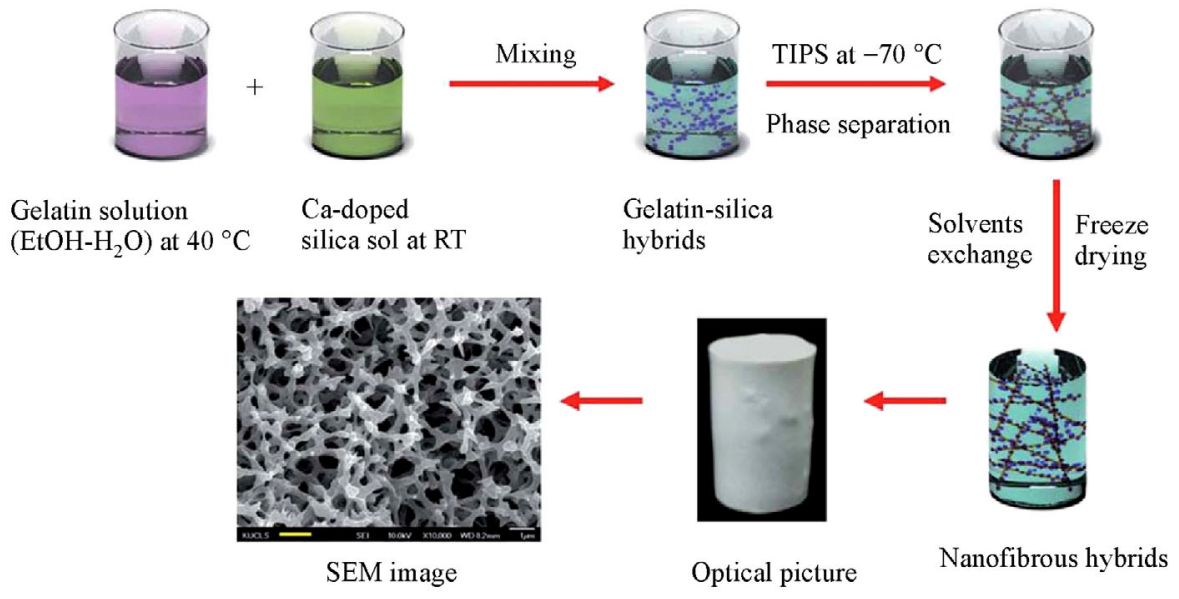

Fig. 6 Schematic diagram showing an experimental procedure for producing nanofibrous gelatin-silica hybrid scaffolds by the thermally induced phase separation (TIPS) technique using the mixtures of the gelatin solution and sol-gel derived silica sol. Reproduced from Ref. [59] with permission from the Royal Society of Chemistry.

demonstrated promising applications in regeneration of soft tissue due to their low mechanical strength or poor bioactivity [70]. To make these elastomers effective for a wider number of biomedical applications, developing hybrid polymers has become an attractive option to obtain biodegradable elastomers with optimized properties to meet different tissue-specific requirements.

PGS-PCL hybrid elastomers have been developed successfully by solvent electrospinning. The incorporation of PCL significantly enhanced formation of the nanofibrous structure and the hybrid materials showed mechanical properties in the range of human aortic valve tissues [71]. Gelatin was also added into PGS elastomer to fabricate hybrid polymers for tissue regeneration. The addition of gelatin significantly enhanced the mechanical properties and bioactivity of PGS elastomers [72]. Although polymer-polymer hybrid elastomers have been well developed, their limited elastomeric behavior and 
mechanical strength still prevent their wide application in bone tissue regeneration.

To overcome the limitations of polymer-based elastomers, inorganic phase reinforced hybrid polymer elastomers have been developed in recent years [73-75]. As osteoconductive biomaterials, hydroxyapatite nanoparticles were incorporated into PCD-based elastomers to fabricate composites for orthopedic implants [76]. Uniform distribution of HA in the polymer matrix significantly enhanced the mechanical properties and osteoconductive biocompatibility of PCD-HA hybrid elastomers. Meltderived bioglass particles were also introduced into PGS elastomers to improve their range of biomedical applications [77]. Bioglass particles efficiently enhanced the elastomeric strain and cellular biocompatibility of PGS. These hybrid elastomers still have the intrinsic problem of poor interface intensity between the inorganic phase and polymers. Therefore, our group introduced bioactive silica into PCD elastomers through a one-step thermal polymerization method $[30,31,78,79]$. The inorganic silica phase was bonded with the PCD polymer chain through covalent bonds. The resulting hybrid polycitrate-silicon (PCS) elastomers demonstrated significantly improved elasto- meric behavior, mechanical strength and cellular biocompatibility (Fig. 7) [30]. SBGS-based PGS hybrid elastomers were also fabricated successfully through the direct hybridization of SBGS and PGS solution [29]. SBGS-PGS hybrid elastomers exhibited significantly enhanced mechanical properties, biominerialization and cellular biocompatibility (Fig. 8). The inorganic phasegrafted PGS and PCD hybrid elastomers have shown promise for applications in bone tissue regeneration.

\section{Electroactive hybrid polymers}

Conducting polymers are organic polymers that possess electrical, magnetic and optical properties that are similar to metal, while maintaining desirable mechanical properties as well as ease of processing of polymers [80,81]. Recently, it was found that conductive polymers could tune the properties of cells in electrically sensitive tissues under electrical stimulation, including neural, muscle, cardiac, and bone [82-84]. Regenerative biomaterials for the treatment of bone diseases that need surgical intervention have attracted more attention, particularly with extended life expectancies. Scaffolds that regulate cellular behavior
A
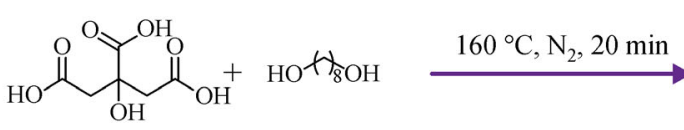
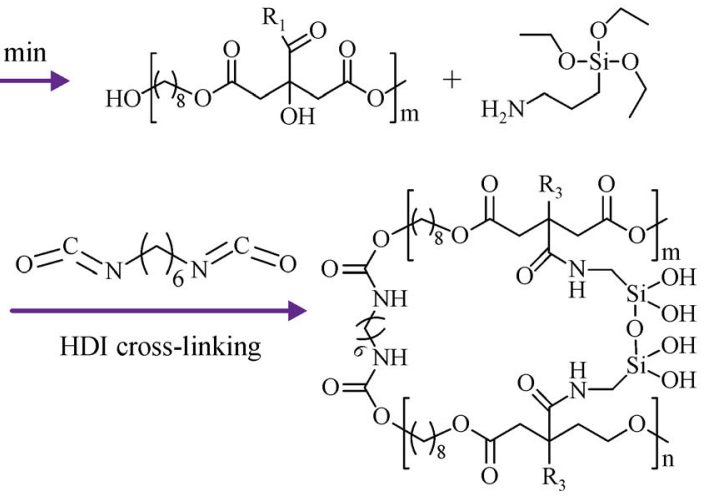

$\mathrm{R}_{1}=\mathrm{H} \quad$ or $>\mathrm{O} \chi_{8} \mathrm{OH} \quad \mathrm{R}_{2}=-\mathrm{OH}$ or $-\mathrm{OC}_{2} \mathrm{H}_{5}$ $\mathrm{R}_{2}=-\mathrm{OH}$ or $-\mathrm{O}_{\mathrm{O}}^{\mathrm{N}}+\mathrm{H}_{6}^{\mathrm{N}} \prod_{\mathrm{O}}^{\mathrm{H}}$
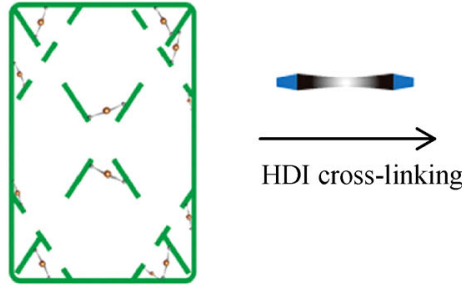

HDI cross-linking

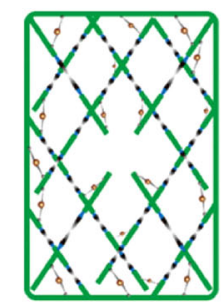

Urethane bond

Fig. 7 Synthesis of multifunctional silica-poly(citrate)-based hybrid prepolymers and elastomers. (A,B) Fabrication of multifunctional silica-poly (citrate) (MSPC) and crosslinked MSPC (CMSPC) elastomers by polycondensation of citric acid (CA), 1,8-octylene glycol (OD), aminosilane (AS), as well as the chemical crosslinking with hexamethylene diisocyanate (HDI) and (C) schematic diagram showing the formation of CMSPC hybrid elastomers matrix. Reproduced from Ref. [30] with permission. 
A

$\overbrace{\mathrm{OH}}^{\stackrel{\mathrm{OH}}{\mathrm{HOHO}}}$<smiles>[R]OCOC(=O)CCC(=O)OC(C)(C)C</smiles><smiles>CCO[Si](OCC)(OCC)OCC</smiles><smiles>CCCCP</smiles>

\section{HO}

$$
\mathrm{R}=\mathrm{H} \text {, polymer chain }
$$

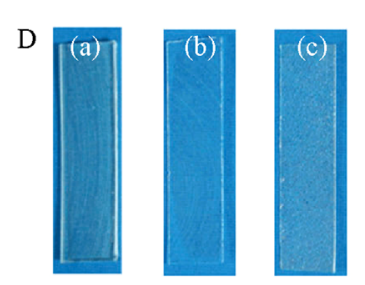

$\mathrm{OH}$
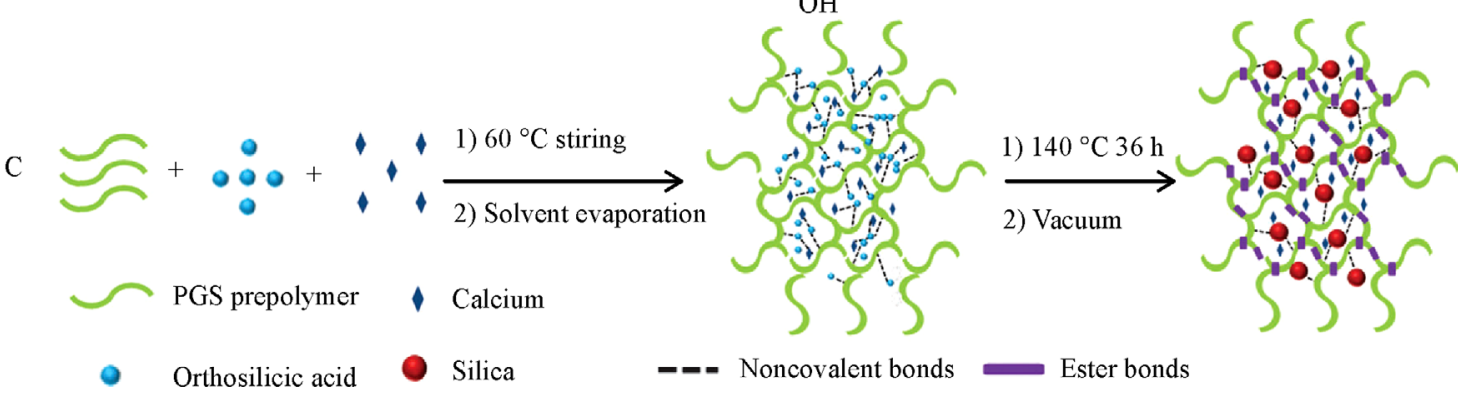

Noncovalent bonds

Ester bonds

Fig. 8 Schematic illustration for preparing poly(glycerol sebacate)-silica-calcium (PGSSC) hybrid elastomers. (A) Synthesis of PGS pre-polymers; (B) formation of silica-based bioactive glass sols; (C) fabrication of PGSSC hybrid elastomers; (D) optical images of PGS and PGSSC hybrid elastomers: (a) PGS; (b) PGS15mol\%Si (PGS15Si); and (c) PGS-15mol\%Si-20mol\%Ca (PGS15Si20Ca). Reproduced from Ref. [29] with permission from the Royal Society of Chemistry.

are particularly interesting for such applications [85-87]. A 3-D conductive scaffold that can locally deliver an electrical signal is needed. 3D conductive scaffolds were prepared using poly(3,4-ethylenedioxythiophene) poly(4styrene sulfonate) (PEDOT:PSS), gelatin, and bioactive glass [88]. Introduction of PEDOT:PSS enhanced the physiochemical stability and improved mechanical properties of the composite. Increasing the content of PEDOT: PSS in the scaffolds improved cell viability. Together, these results indicated that these conductive scaffolds exhibited more favorable structural properties for bone repair. The use of conducting polymers loaded with a bioactive molecule has been an emerging approach to functional biomaterial use in tissue regeneration. Chondroitin sulfate (CS)-doped polypyrrole (PPy) was coated via an in situ chemical oxidative polymerization onto the non-conductive polylactide to fabricate novel osteogenic scaffolds [89]. Electrical conductivity of PPy-coated polylactide (PPy-PLA) scaffolds was obvious, but it decreased with time due to de-doping.

\section{Applications in bone tissue regeneration}

Biomaterials-based bone regeneration aims to develop bioactive bone-substitutes that repair damaged issue and restore tissue functionality. Native bone ECM is a hybrid structure that consists of a polymer and inorganic phase. Therefore, biodegradable hybrid polymer biomaterials with representative nanostructures are desirable for bone tissue regeneration [90]. Inorganic phase reinforced hybrid biomaterials with multifunctional properties have demonstrated enhanced bone-binding ability, osteoblast activity, and bone regeneration potential as compared to pure biodegradable polymers [91]. Here, we review the recent development of biodegradable hybrid polymer biomaterials for osteoblastic proliferation, differentiation, and in vivo bone regeneration.

Silicon-based BG particles with microscale and nanoscale sizes have been employed to enhance biominerialization and biocompatibility [41,43]. As shown in Fig. 6, hybrid polymers reinforced with BG microparticles or nanoparticles could efficiently induce deposition of biological apatite after soaking in SBF [41]. Osteoblast attachment was also improved on the hybrid BGN-PCL, as compared to PCL scaffold alone [43]. In addition to bioactive glass-based hybrid polymer, the apatite-based polymer also showed enhanced osteoblastic activity (Fig. 9). After 1 and 4 weeks culture of MC3T3-E1 cells on nanofibrous gelatin-apatite hybrid scaffolds (NFgelatin/apatite) and pure NF-gelatin scaffolds, cells grown on the hybrid scaffolds showed significantly increased expression of genes for bone sialoprotein (BSP) and osteocalcin (OCN) (Fig.10) [49]. In vivo experimentation demonstrated that the incorporation of osteoconductive components can significantly improve bone formation. For example, compared with pure poly 

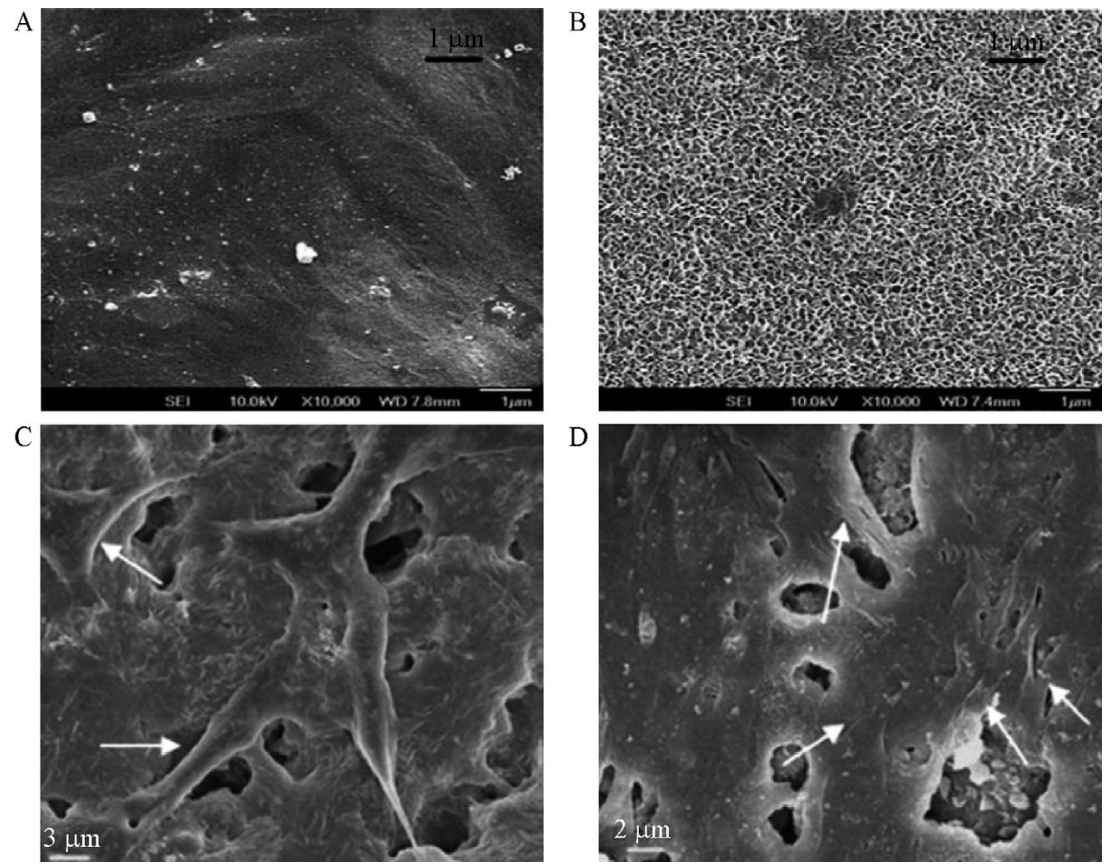

Fig. 9 In vitro biomineralization activity and osteoblast biocompatibility (MC3T3-E1) of BG micro-nanoscale particles-PCL hybrid polymers. (A, B) Apatite formation on surface of PCL (A) and BG-PCL (B) after soaking in SBF for 7 days; (C, D) Cell attachment morphology on the surface of PCL (C) and BG-PCL (D) after culture for 3 days. Reproduced from Refs. [41] and [43] with permission.
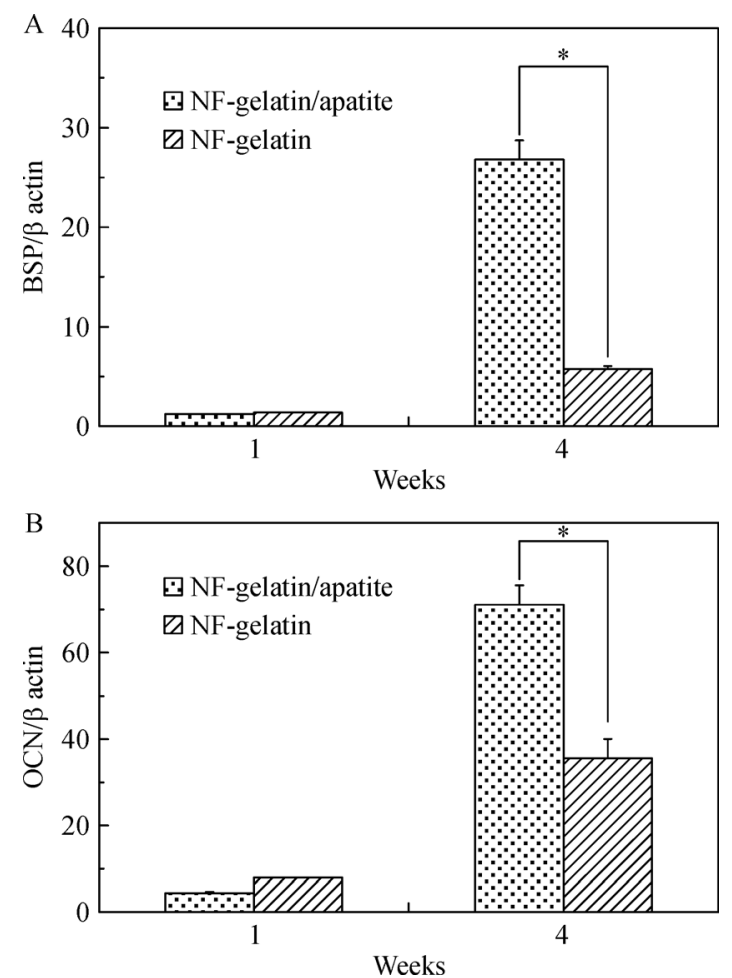

Fig. 10 Quantitative RT-PCR results of bone sialoprotein (BSP)(A) and osteocalcin $(\mathrm{OCN})(\mathrm{B})$ gene expression. MC3T3-E1 cells were cultured on NF-gelatin and NF-gelatin/apatite scaffolds for 1 and 4 weeks. The $Y$-axis of the figure is the gene expression results normalized by $\beta$ actin. * represents statistically significant differences $(P<0.05)$. Reproduced from Ref. [49] with permission. (lactide-co-glycolide) (PLGA), amorphous tricalcium phosphate nanoparticles reinforced PLGA (PLGA-TCP) nanocomposites enhanced the rapid regeneration of bone defects in a New Zealand white rabbit model (Fig. 11) [92].

As compared to osteoconductive particle-based hybrid polymers, silica-based sol-polymers possessed uniform nanostructure distribution and inorganic-organic interface, which could mimic the structure of native bone ECM. Silica-based chitosan hybrid polymer has been used to guide bone tissue regeneration successfully [93]. As compared to pure chitosan, new bone formation was significantly enhanced by the hybrid polymer while the hybrid membrane was degraded after 3 weeks implantation at bone defect sites (Fig. 12). A significantly higher rate of bone formation was observed for the hybrid (93\%) but not the chitosan membrane (60\%) [93]. Due to the inherent elastomeric behavior of native bone, elastomeric hybrid biomaterials are appealing for applications in bone regeneration [94]. Our group developed silicon-based polymer elastomers with controlled biodegradation for applications in bone regeneration [29-31]. The results demonstrated that poly(citrate-siloxane) (PCS) hybrid elastomers significantly enhanced attachment and proliferation of various cells, including cells derived from both hard and soft tissue [30,31]. PCS-based hybrid polymer could also significantly enhance osteoblastic differentiation, cellular biominerialization of MC3T3-E1 cells $[78,79]$. PCS-based hybrid biomaterials have shown 


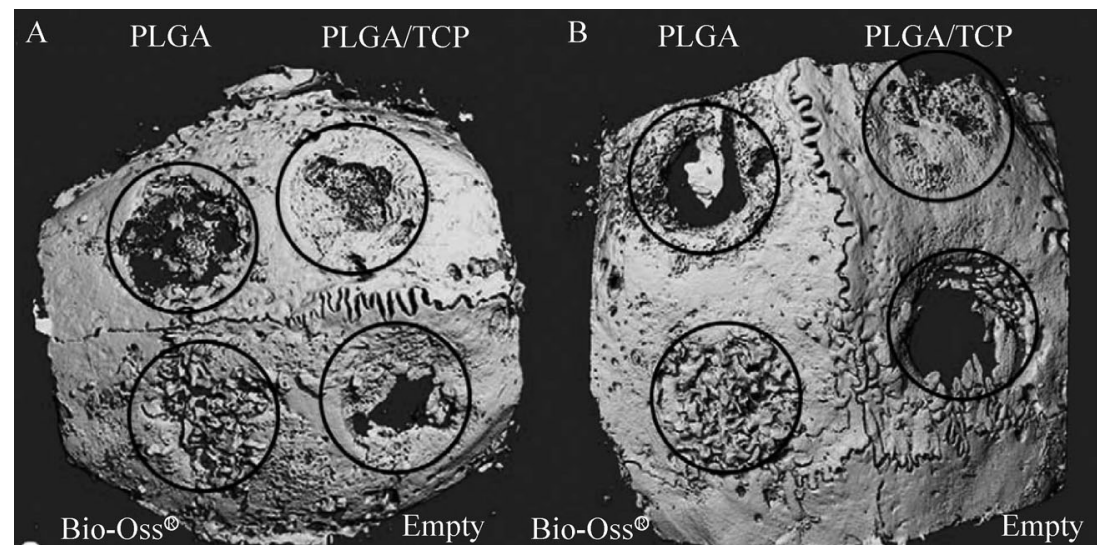

Fig. 11 Micro-computed tomography of the cranial defects (diameter $=6 \mathrm{~mm}$ ) in New Zealand White rabbits after 4-week implantation using PLGA, PLGA/TCP composites. (A, B) Two examples of the CT of the entire cranial bone are shown. Defect margins and treatment modalities are indicated. Adapted from Ref. [92] with permission.
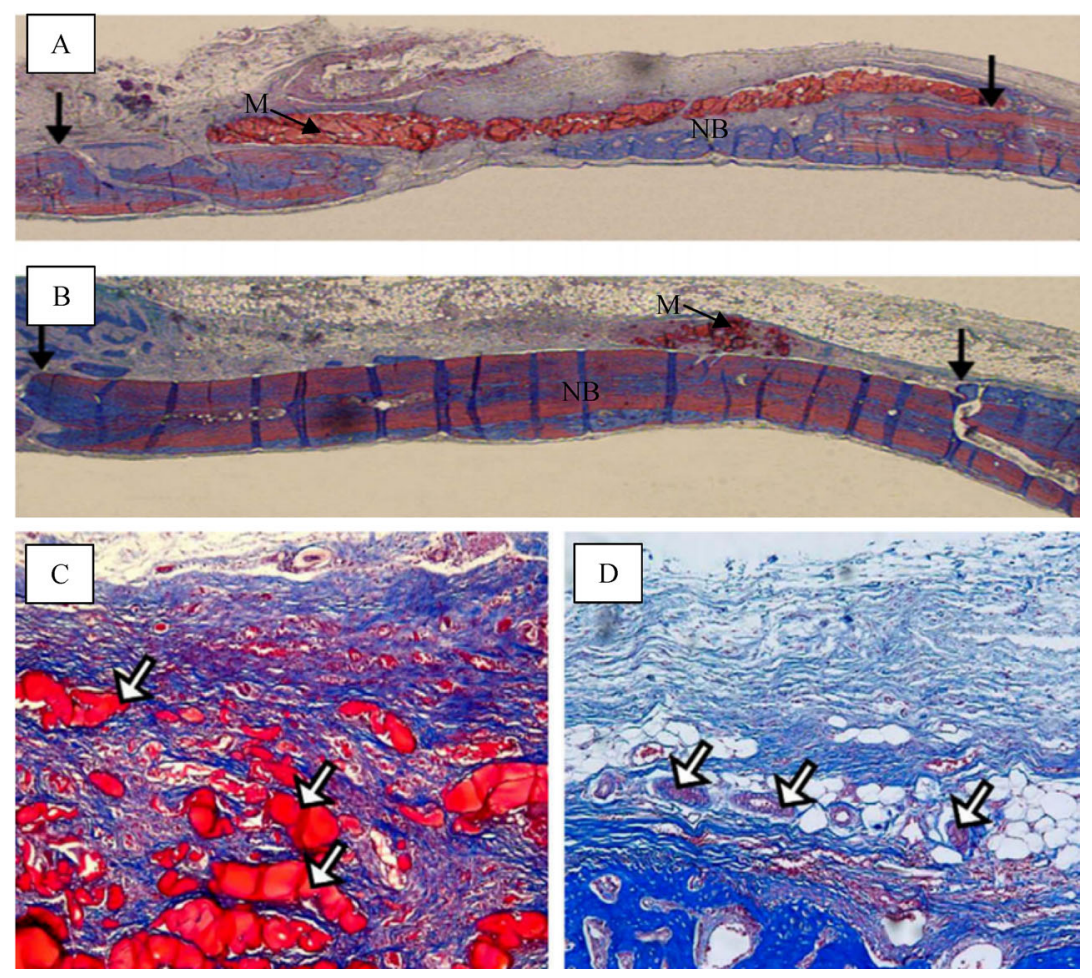

Fig. 12 Optical micrographs of the rat bone tissue regeneration responses after the 3 weeks implantation of the membranes: (A, C) pure chitosan and $(B, D)$ the chitosan-silica xerogel hybrid. The fresh-formed bone tissue was revealed in blue, the calcified bones and materials were stained in red. Reproduced from Ref. [93] with permission.

promising potential for in vivo bone tissue regeneration. Additional in vivo experiments should be carried out to evaluate the potential value of PCS-based hybrid biomaterials.

Proliferation and osteogenic differentiation of human adipose stem cells (hASCs) on the coated and conductive scaffolds was compared to non-coated polylactide scaffolds under electrical stimulation. The conductive hybrid scaffolds greatly enhanced hASC proliferation compared to pure PLA scaffolds [89]. Alkaline phosphatase (ALP) activity of hASCs seeded on PLA-PPy scaffolds was generally higher; however, electrical stimulation did not 
show a significant effect on hASCs. These results highlighted the potential application of PPy-coated PLA scaffolds for bone regeneration. Mesenchymal stem cells (MSCs) have great potential and are commonly used progenitor cells in bone tissue engineering. Osteogenic differentiation of MSCs can be guided by various types of biomaterials. Our group found that the electroactive biodegradable copolymers can enhance osteogenic differentiation of bone marrow derived MSCs (BMSCs) [95]. These copolymers were composed of polylactide and tunable contents of conductive aniline tetramer. Culture of BMSCs on the electroactive copolymer films indicated that these copolymers were not cytotoxic, in fact proliferation of BMSCs was significantly enhanced. Osteogenic differentiation of BMSCs showed that the electroactive copolymers greatly promoted osteogenic differentiation compared to pure PLA with respect to expression of ALP, OPN, and Runx 2 and deposition of calcium measured by von Kossa staining. The electroactive copolymer surface can adsorb more protein than pure PLA, which may be a factor that enhanced proliferation and differentiation of MSCs. These results indicated that the electroactive degradable polymers based on polylactide and aniline tetramer have great potential as scaffolding materials for bone regeneration.

\section{Summary and perspectives}

Degradable hybrid polymer biomaterials with osteoconductivity, biomimetic elastomeric behavior and electroactivity have shown promise in applications in bone tissue repair and regeneration. However, to meet the requirements of efficient bone regeneration, there are still many areas in need of improvement for these polymer hybrid biomaterials. First, high osteoinductive activity should be incorporated into these hybrid polymers. Second, maintaining high mechanical strength of hybrid polymers while preserving their elastomeric behavior should be prioritized. Third, other functions including antibacterial activity and bioimaging ability should be also considered in the design of next generation hybrid polymer biomaterials.

\section{Acknowledgements}

This work was financially supported by US DOD (No. W81XWH12-2-0008), the National Institutes of Health (Nos. NIDCR DE022327 and T32 HD007505), National Natural Science Foundation of China (Nos. 51502237, 21304073, and 51673155), and Xi'an Jiaotong University.

\section{Compliance with ethics guidelines}

Bo Lei, Baolin Guo, Kunal J. Rambhia, and Peter X. Ma declare that they have no financial conflicts of interest. This manuscript is a review article and does not involve a research protocol requiring approval by a relevant institutional review board or ethics committee.

Open Access This article is distributed under the terms of the Creative Commons Attribution 4.0 International License (http:// creativecommons.org/licenses/by/4.0/), which permits unrestricted use, distribution, and reproduction in any medium, provided the appropriate credit is given to the original author(s) and the source, and a link is provided to the Creative Commons license, which indicates if changes are made.

\section{References}

1. Watt FM, Huck WTS. Role of the extracellular matrix in regulating stem cell fate. Nat Rev Mol Cell Biol 2013; 14(8): 467-473

2. Erickson IE, Kestle SR, Zellars KH, Farrell MJ, Kim M, Burdick JA, Mauck RL. High mesenchymal stem cell seeding densities in hyaluronic acid hydrogels produce engineered cartilage with native tissue properties. Acta Biomater 2012; 8(8): 3027-3034

3. Lee SS, Huang BJ, Kaltz SR, Sur S, Newcomb CJ, Stock SR, Shah RN, Stupp SI. Bone regeneration with low dose BMP-2 amplified by biomimetic supramolecular nanofibers within collagen scaffolds. Biomaterials 2013; 34(2): 452-459

4. Dorozhkin SV. Calcium orthophosphate-containing biocomposites and hybrid biomaterials for biomedical applications. J Funct Biomater 2015; 6(3): 708-832

5. Wu W, Wang WG, Li JS. Star polymers: advances in biomedical applications. Prog Polym Sci 2015; 46: 55-85

6. Nicolas J, Mura S, Brambilla D, Mackiewicz N, Couvreur P. Design, functionalization strategies and biomedical applications of targeted biodegradable/biocompatible polymer-based nanocarriers for drug delivery. Chem Soc Rev 2013; 42(3): 1147-1235

7. Tian HY, Tang ZH, Zhuang XL, Chen XS, Jing XB. Biodegradable synthetic polymers: preparation, functionalization and biomedical application. Prog Polym Sci 2012; 37(2): 237-280

8. Pan Z, Ding J. Poly(lactide-co-glycolide) porous scaffolds for tissue engineering and regenerative medicine. Interface Focus 2012; 2(3): 366-377

9. Igwe JC, Mikael PE, Nukavarapu SP. Design, fabrication and in vitro evaluation of a novel polymer-hydrogel hybrid scaffold for bone tissue engineering. J Tissue Eng Regen Med 2014; 8(2): 131142

10. Venkatesan J, Bhatnagar I, Manivasagan P, Kang KH, Kim SK. Alginate composites for bone tissue engineering: a review. Int J Biol Macromol 2015; 72: 269-281

11. Venkatesan J, Vinodhini PA, Sudha PN, Kim SK. Chitin and chitosan composites for bone tissue regeneration. Adv Food Nutr Res 2014;73: 59-81 PMID: 25300543

12. Yunus Basha R, Sampath Kumar TS, Doble M. Design of biocomposite materials for bone tissue regeneration. Mater Sci Eng C 2015; 57: 452-463

13. Sun F, Zhou H, Lee J. Various preparation methods of highly porous hydroxyapatite/polymer nanoscale biocomposites for bone regeneration. Acta Biomater 2011; 7(11): 3813-3828

14. Gkioni K, Leeuwenburgh SCG, Douglas TEL, Mikos AG, Jansen 
JA. Mineralization of hydrogels for bone regeneration. Tissue Eng Part B Rev 2010; 16(6): 577-585

15. Wei Q, Lu J, Wang Q, Fan H, Zhang X. Novel synthesis strategy for composite hydrogel of collagen/hydroxyapatite-microsphere originating from conversion of $\mathrm{CaCO}_{3}$ templates. Nanotechnology 2015; 26(11): 115605

16. Vo TN, Shah SR, Lu S, Tatara AM, Lee EJ, Roh TT, Tabata Y, Mikos AG. Injectable dual-gelling cell-laden composite hydrogels for bone tissue engineering. Biomaterials 2016; 83: 1-11

17. Nejadnik MR, Mikos AG, Jansen JA, Leeuwenburgh SCG. Facilitating the mineralization of oligo(poly(ethylene glycol) fumarate) hydrogel by incorporation of hydroxyapatite nanoparticles. J Biomed Mater Res A 2012; 100(5): 1316-1323

18. Samavedi S, Whittington AR, Goldstein AS. Calcium phosphate ceramics in bone tissue engineering: a review of properties and their influence on cell behavior. Acta Biomater 2013; 9(9): 8037-8045

19. Wei G, Jin Q, Giannobile WV, Ma PX. The enhancement of osteogenesis by nano-fibrous scaffolds incorporating rhBMP-7 nanospheres. Biomaterials 2007; 28(12): 2087-2096

20. Zhang R, Ma PX. Poly( $\alpha$-hydroxyl acids)/hydroxyapatite porous composites for bone-tissue engineering. I. Preparation and morphology. J Biomed Mater Res 1999; 44(4): 446-455

21. Kango S, Kalia S, Celli A, Njuguna J, Habibi Y, Kumar R. Surface modification of inorganic nanoparticles for development of organicinorganic nanocomposites - a review. Prog Polym Sci 2013; 38(8): 1232-1261

22. Pina S, Oliveira JM, Reis RL. Natural-based nanocomposites for bone tissue engineering and regenerative medicine: a review. Adv Mater 2015; 27(7): 1143-1169

23. Sahoo NG, Pan YZ, Li L, He CB. Nanocomposites for bone tissue regeneration. Nanomedicine (Lond) 2013; 8(4): 639-653

24. Ma PX, Zhang R, Xiao G, Franceschi R. Engineering new bone tissue in vitro on highly porous poly $(\alpha$-hydroxyl acids)/hydroxyapatite composite scaffolds. J Biomed Mater Res 2001; 54(2): 284-293

25. Shinzato S, Nakamura T, Ando K, Kokubo T, Kitamura $\mathrm{Y}$. Mechanical properties and osteoconductivity of new bioactive composites consisting of partially crystallized glass beads and poly (methyl methacrylate). J Biomed Mater Res 2002; 60(4): 556-563

26. Koleganova VA, Bernier SM, Dixon SJ, Rizkalla AS. Bioactive glass/polymer composite materials with mechanical properties matching those of cortical bone. J Biomed Mater Res A 2006; 77 (3): $572-579$

27. Marcolongo M, Ducheyne P, Garino J, Schepers E. Bioactive glass fiber/polymeric composites bond to bone tissue. J Biomed Mater Res 1998; 39(1): 161-170

28. Kerativitayanan P, Gaharwar AK. Elastomeric and mechanically stiff nanocomposites from poly(glycerol sebacate) and bioactive nanosilicates. Acta Biomater 2015; 26: 34-44

29. Zhao X, Wu Y, Du Y, Chen X, Lei B, Xue Y, Ma PX. A highly bioactive and biodegradable poly(glycerol sebacate)-silica glass hybrid elastomer with tailored mechanical properties for bone tissue regeneration. J Mater Chem B Mater Biol Med 2015; 3(16): 32223233

30. Du YZ, Yu M, Ge J, Ma PX, Chen XF, Lei B. Development of a multifunctional platform based on strong, intrinsically photoluminescent and antimicrobial silica-poly(citrates)-based hybrid biode- gradable elastomers for bone regeneration. Adv Funct Mater 2015; 25(31): 5016-5029

31. Du YZ, Ge J, Shao YP, Ma PX, Chen XF, Lei B. Development of silica grafted poly(1,8-octanediol-co-citrates) hybrid elastomers with highly tunable mechanical properties and biocompatibility. J Mater Chem B Mater Biol Med 2015; 3(15): 2986-3000

32. Balint R, Cassidy NJ, Cartmell SH. Conductive polymers: towards a smart biomaterial for tissue engineering. Acta Biomater 2014; 10(6): 2341-2353

33. Hopley EL, Salmasi S, Kalaskar DM, Seifalian AM. Carbon nanotubes leading the way forward in new generation 3D tissue engineering. Biotechnol Adv 2014; 32(5): 1000-1014

34. Liu X, Holzwarth JM, Ma PX. Functionalized synthetic biodegradable polymer scaffolds for tissue engineering. Macromol Biosci 2012; 12(7): 911-919

35. Jones JR. Review of bioactive glass: from Hench to hybrids. Acta Biomater 2013; 9(1): 4457-4486

36. Lei B, Chen XF, Wang YJ, Zhao N. Synthesis and in vitro bioactivity of novel mesoporous hollow bioactive glass microspheres. Mater Lett 2009; 63(20): 1719-1721

37. Lei B, Chen X, Wang Y, Zhao N, Du C, Fang L. Surface nanoscale patterning of bioactive glass to support cellular growth and differentiation. J Biomed Mater Res A 2010; 94(4): 1091-1099

38. Chen XF, Lei B, Wang YJ, Zhao N. Morphological control and in vitro bioactivity of nanoscale bioactive glasses. J Non-Cryst Solids 2009; 355(13): 791-796

39. Zakaria SM, Sharif Zein SH, Othman MR, Yang F, Jansen JA. Nanophase hydroxyapatite as a biomaterial in advanced hard tissue engineering: a review. Tissue Eng Part B Rev 2013; 19(5): 431-441

40. Boccaccini AR, Erol M, Stark WJ, Mohn D, Hong ZK, Mano JF. Polymer/bioactive glass nanocomposites for biomedical applications: a review. Compos Sci Technol 2010; 70(13): 1764-1776

41. Lei B, Shin KH, Noh DY, Koh YH, Choi WY, Kim HE. Bioactive glass microspheres as reinforcement for improving the mechanical properties and biological performance of poly(e-caprolactone) polymer for bone tissue regeneration. J Biomed Mater Res Part B Appl Biomater 2012; 100B (4): 967-975

42. Lei B, Chen XF, Han X, Zhou JA. Versatile fabrication of nanoscale sol-gel bioactive glass particles for efficient bone tissue regeneration. J Mater Chem 2012; 22(33): 16906-16913

43. Lei B, Shin KH, Noh DY, Jo IH, Koh YH, Kim HE, Kim SE. Solgel derived nanoscale bioactive glass (NBG) particles reinforced poly( $\varepsilon$-caprolactone) composites for bone tissue engineering. Mater Sci Eng C 2013; 33(3): 1102-1108

44. Roohani-Esfahani SI, Nouri-Khorasani S, Lu Z, Appleyard R, Zreiqat $\mathrm{H}$. The influence hydroxyapatite nanoparticle shape and size on the properties of biphasic calcium phosphate scaffolds coated with hydroxyapatite-PCL composites. Biomaterials 2010; 31(21): 5498-5509

45. Rahaman MN, Day DE, Bal BS, Fu Q, Jung SB, Bonewald LF, Tomsia AP. Bioactive glass in tissue engineering. Acta Biomater 2011; 7(6): 2355-2373

46. Peter M, Binulal NS, Nair SV, Selvamurugan N, Tamura H, Jayakumar R. Novel biodegradable chitosan-gelatin/nano-bioactive glass ceramic composite scaffolds for alveolar bone tissue engineering. Chem Eng J 2010; 158(2): 353-361

47. Mozafari M, Moztarzadeh F, Rabiee M, Azami M, Maleknia S, 
Tahriri M, Moztarzadeh Z, Nezafati N. Development of macroporous nanocomposite scaffolds of gelatin/bioactive glass prepared through layer solvent casting combined with lamination technique for bone tissue engineering. Ceram Int 2010; 36(8): 2431-2439

48. Hong Z, Reis RL, Mano JF. Preparation and in vitro characterization of scaffolds of poly(L-lactic acid) containing bioactive glass ceramic nanoparticles. Acta Biomater 2008; 4(5): 1297-1306

49. Liu X, Smith LA, Hu J, Ma PX. Biomimetic nanofibrous gelatin/ apatite composite scaffolds for bone tissue engineering. Biomaterials 2009; 30(12): 2252-2258

50. He C, Xiao G, Jin X, Sun C, Ma PX. Electrodeposition on nanofibrous polymer scaffolds: rapid mineralization, tunable calcium phosphate composition and topography. Adv Funct Mater 2010; 20(20): 3568-3576

51. Lei B, Wang L, Chen XF, Chae SK. Biomimetic and molecular level-based silicate bioactive glass-gelatin hybrid implants for loading-bearing bone fixation and repair. J Mater Chem B Mater Biol Med 2013; 1(38): 5153-5162

52. Chen J, Que W, Xing Y, Lei B. Molecular level-based bioactive glass-poly (caprolactone) hybrids monoliths with porous structure for bone tissue repair. Ceram Int 2015; 41(2): 3330-3334

53. Xie M, Ge J, Lei B, Zhang Q, Chen X, Ma PX. Star-shaped, biodegradable, and elastomeric PLLA-PEG-POSS hybrid membrane with biomineralization activity for guiding bone tissue regeneration. Macromol Biosci 2015; 15(12): 1656-1662

54. Chen J, Du Y, Que W, Xing Y, Chen X, Lei B. Crack-free polydimethylsiloxane-bioactive glass-poly(ethylene glycol) hybrid monoliths with controlled biomineralization activity and mechanical property for bone tissue regeneration. Colloids Surf B Biointerfaces 2015; 136: 126-133

55. Chen J, Du YZ, Que WX, Xing YL, Lei B. Content-dependent biomineralization activity and mechanical properties based on polydimethylsiloxane-bioactive glass-poly(caprolactone) hybrids monoliths for bone tissue regeneration. Rsc Adv. 2015; 5(75): 61309-61317

56. Lei B, Shin KH, Moon YW, Noh DY, Koh YH, Jin Y, Kim HE. Synthesis and bioactivity of sol-gel derived porous, bioactive glass microspheres using chitosan as novel biomolecular template. J Am Ceram Soc 2012; 95(1): 30-33

57. Mahony O, Tsigkou O, Ionescu C, Minelli C, Ling L, Hanly R, Smith ME, Stevens MM, Jones JR. Silica-gelatin hybrids with tailorable degradation and mechanical properties for tissue regeneration. Adv Funct Mater 2010; 20(22): 3835-3845

58. Lei B, Shin KH, Jo IH, Koh YH, Kim HE. Highly porous gelatinsilica hybrid scaffolds with textured surfaces using new direct foaming/freezing technique. Mater Chem Phys 2014; 145(3): 397402

59. Lei B, Shin KH, Noh DY, Jo IH, Koh YH, Choi WY, Kim HE. Nanofibrous gelatin-silica hybrid scaffolds mimicking the native extracellular matrix (ECM) using thermally induced phase separation. J Mater Chem 2012; 22(28): 14133-14140

60. Xue YM, Wang L, Shao YP, Yan J, Chen XF, Lei B. Facile and green fabrication of biomimetic gelatin-siloxane hybrid hydrogel with highly elastic properties for biomedical applications. Chem Eng J 2014; 251: 158-164

61. Duan S, Yang X, Mei F, Tang Y, Li X, Shi Y, Mao J, Zhang H, Cai Q. Enhanced osteogenic differentiation of mesenchymal stem cells on poly(L-lactide) nanofibrous scaffolds containing carbon nanomaterials. J Biomed Mater Res A 2015; 103(4): 1424-1435

62. Sitharaman B, Shi X, Walboomers XF, Liao H, Cuijpers V, Wilson LJ, Mikos AG, Jansen JA. In vivo biocompatibility of ultra-short single-walled carbon nanotube/biodegradable polymer nanocomposites for bone tissue engineering. Bone 2008; 43(2): 362-370

63. Park S, Park J, Jo I, Cho SP, Sung D, Ryu S, Park M, Min KA, Kim J, Hong S, Hong BH, Kim BS. In situ hybridization of carbon nanotubes with bacterial cellulose for three-dimensional hybrid bioscaffolds. Biomaterials 2015; 58: 93-102

64. Siqueira IAWB, Corat MAF, Cavalcanti B, Ribeiro Neto WA, Martin AA, Bretas RE, Marciano FR, Lobo AO. In vitro and in vivo studies of novel poly(D,L-lactic acid), superhydrophilic carbon nanotubes, and nanohydroxyapatite scaffolds for bone regeneration. ACS Appl Mater Interfaces 2015; 7(18): 9385-9398

65. Mikael PE, Amini AR, Basu J, Josefina Arellano-Jimenez M, Laurencin CT, Sanders MM, Barry Carter C, Nukavarapu SP. Functionalized carbon nanotube reinforced scaffolds for bone regenerative engineering: fabrication, in vitro and in vivo evaluation. Biomed Mater 2014; 9(3): 035001

66. Hirata E, Ménard-Moyon C, Venturelli E, Takita H, Watari F, Bianco A, Yokoyama A. Carbon nanotubes functionalized with fibroblast growth factor accelerate proliferation of bone marrowderived stromal cells and bone formation. Nanotechnology 2013; 24 (43): 435101

67. Das B, Chattopadhyay P, Maji S, Upadhyay A, Das Purkayastha M, Mohanta CL, Maity TK, Karak N. Bio-functionalized MWCNT/ hyperbranched polyurethane bionanocomposite for bone regeneration. Biomed Mater 2015; 10(2): 025011

68. Lei B, Shin KH, Koh YH, Kim HE. Porous gelatin-siloxane hybrid scaffolds with biomimetic structure and properties for bone tissue regeneration. J Biomed Mater Res B Appl Biomater 2014; 102(7): $1528-1536$

69. Nettles DL, Chilkoti A, Setton LA. Applications of elastin-like polypeptides in tissue engineering. Adv Drug Deliv Rev 2010; 62 (15): 1479-1485

70. Chen QZ, Liang SL, Thouas GA. Elastomeric biomaterials for tissue engineering. Prog Polym Sci 2013; 38(3-4): 584-671

71. Sant S, Hwang CM, Lee SH, Khademhosseini A. Hybrid PGS-PCL microfibrous scaffolds with improved mechanical and biological properties. J Tissue Eng Regen Med 2011; 5(4): 283-291

72. Kharaziha M, Nikkhah M, Shin SR, Annabi N, Masoumi N, Gaharwar AK, Camci-Unal G, Khademhosseini A. PGS:Gelatin nanofibrous scaffolds with tunable mechanical and structural properties for engineering cardiac tissues. Biomaterials 2013; 34 (27): 6355-6366

73. Bokobza L. Mechanical, electrical and spectroscopic investigations of carbon nanotube-reinforced elastomers. Vib Spectrosc 2009; 51 (1): $52-59$

74. Pei AH, Malho JM, Ruokolainen J, Zhou Q, Berglund LA. Strong nanocomposite reinforcement effects in polyurethane elastomer with low volume fraction of cellulose nanocrystals. Macromolecules 2011; 44(11): 4422-4427

75. Paul DR, Mark JE. Fillers for polysiloxane (“silicone") elastomers. Prog Polym Sci 2010; 35(7): 893-901

76. Moradi A, Dalilottojari A, Pingguan-Murphy B, Djordjevic I. Fabrication and characterization of elastomeric scaffolds comprised 
of a citric acid-based polyester/hydroxyapatite microcomposite. Mater Des 2013; 50: 446-450

77. Liang SL, Cook WD, Thouas GA, Chen QZ. The mechanical characteristics and in vitro biocompatibility of poly(glycerol sebacate)-bioglass elastomeric composites. Biomaterials 2010; 31 (33): 8516-8529

78. Du Y, Yu M, Chen X, Ma PX, Lei B. Development of biodegradable poly(citrate)-polyhedral oligomeric silsesquioxanes hybrid elastomers with high mechanical properties and osteogenic differentiation activity. ACS Appl Mater Interfaces 2016; 8(5): 3079-3091

79. Du Y, Xue Y, Ma PX, Chen X, Lei B. Biodegradable, elastomeric, and intrinsically photoluminescent poly(silicon-citrates) with high photostability and biocompatibility for tissue regeneration and bioimaging. Adv Healthc Mater 2016; 5(3): 382-392

80. Guimard NK, Gomez N, Schmidt CE. Conducting polymers in biomedical engineering. Prog Polym Sci 2007; 32(8-9): 876-921

81. Patil AO, Heeger AJ, Wudl F. Optical-properties of conducting polymers. Chem Rev 1988; 88(1): 183-200

82. Guo BL, Glavas L, Albertsson AC. Biodegradable and electrically conducting polymers for biomedical applications. Prog Polym Sci 2013; 38(9): 1263-1286

83. Xie M, Wang L, Ge J, Guo B, Ma PX. Strong electroactive biodegradable shape memory polymer networks based on starshaped polylactide and aniline trimer for bone tissue engineering. ACS Appl Mater Interfaces 2015; 7(12): 6772-6781

84. Xie M, Wang L, Guo B, Wang Z, Chen YE, Ma PX. Ductile electroactive biodegradable hyperbranched polylactide copolymers enhancing myoblast differentiation. Biomaterials 2015; 71: 158167

85. Hardy JG, Geissler SA, Aguilar D Jr, Villancio-Wolter MK, Mouser DJ, Sukhavasi RC, Cornelison RC, Tien LW, Preda RC, Hayden RS, Chow JK, Nguy L, Kaplan DL, Schmidt CE. Instructive conductive 3D silk foam-based bone tissue scaffolds enable electrical stimulation of stem cells for enhanced osteogenic differentiation. Macromol Biosci 2015; 15(11): 1490-1496

86. Meng S, Zhang Z, Rouabhia M. Accelerated osteoblast mineraliza- tion on a conductive substrate by multiple electrical stimulation. J Bone Miner Metab 2011; 29(5): 535-544

87. Meng S, Rouabhia M, Zhang Z. Electrical stimulation modulates osteoblast proliferation and bone protein production through heparin-bioactivated conductive scaffolds. Bioelectromagnetics 2013; 34(3): 189-199

88. Yazdimamaghani M, Razavi M, Mozafari M, Vashaee D, Kotturi H, Tayebi L. Biomineralization and biocompatibility studies of bone conductive scaffolds containing poly(3,4-ethylenedioxythiophene): poly(4-styrene sulfonate) (PEDOT:PSS). J Mater Sci Mater Med 2015; 26(12):274

89. Pelto J, Björninen M, Pälli A, Talvitie E, Hyttinen J, Mannerström B, Suuronen Seppanen R, Kellomäki M, Miettinen S, Haimi S. Novel polypyrrole-coated polylactide scaffolds enhance adipose stem cell proliferation and early osteogenic differentiation. Tissue Eng Part A 2013; 19(7-8): 882-892

90. Guo B, Lei B, Li P, Ma PX. Functionalized scaffolds to enhance tissue regeneration. Regen Biomater 2015; 2(1): 47-57

91. Jiang T, Carbone EJ, Lo KWH, Laurencin CT. Electrospinning of polymer nanofibers for tissue regeneration. Prog Polym Sci 2015; 46: $1-24$

92. Schneider OD, Weber F, Brunner TJ, Loher S, Ehrbar M, Schmidlin $\mathrm{PR}$, Stark WJ. In vivo and in vitro evaluation of flexible, cottonwoollike nanocomposites as bone substitute material for complex defects. Acta Biomater 2009; 5(5): 1775-1784

93. Lee EJ, Shin DS, Kim HE, Kim HW, Koh YH, Jang JH. Membrane of hybrid chitosan-silica xerogel for guided bone regeneration. Biomaterials 2009; 30(5): 743-750

94. Xie M, Ge J, Xue Y, Du Y, Lei B, Ma PX. Photo-crosslinked fabrication of novel biocompatible and elastomeric star-shaped inositol-based polymer with highly tunable mechanical behavior and degradation. J Mech Behav Biomed Mater 2015; 51: 163-168

95. Li LC, Yu M, Ma PX, Guo BL. Electroactive degradable copolymers enhancing osteogenic differentiation from bone marrow derived mesenchymal stem cells. J Mater Chem B Mater Biol Med 2016; 4(3): 471-481 